\title{
Re-Thinking Traditional Arab Architecture: A Traditional Approach to Contemporary Living
}

\author{
Aiman Ajaj and Fausto Pugnaloni
}

\begin{abstract}
The aim of this study is analysis the architectural vocabulary which governed the design concept of the traditional Arab architecture and highlighted its distinctive characteristics . A good method as an approach towards a contemporary design concept. The object research is to analyse traditional settlement patterns and building types, and giving many useful indications. especially for solutions aiming at natural climate control. which could serve as a useful foundation upon which to develop new solutions more in keeping with the local economics, environment, and society than those that have replaced the traditional ones. Many traditional techniques could be improved, using new materials and knowledge, rather than totally abandoned. It would be of great benefit also if societies with similar conditions could share their traditional solutions to specific problems. Following appraisal, some solutions may be rejected as inappropriate .
\end{abstract}

Index Terms - Arab traditional hot arid climate architecture contemporary.

\section{INTRODUCTION}

Buildings in developing countries are often designed without taking sufficient account of the climate. Factors such as the urban surroundings or site characteristics, orientation and architectural design of the building, choice of building materials, etc. are not given enough importance. Consequently buildings often have a poor indoor climate, which affects comfort, health and efficiency.

As living standards rise people want to install heating and/or cooling equipment to improve thermal comfort. For buildings not adapted to the climate, the amount of energy to run the equipment, and its cost, will be excessively high, and it will have a negative impact on the environment. The field of traditional architecture offers an abundance of concepts that can be of use today in solving the critical housing situation now facing millions in the Third World, the principles of thermal control through the proper use of structure and materials are well illustrated in traditional buildings which meet the demands of the climate.

The traditional techniques employed are rarely costly in terms of materials or energy and are thus not only largely within the economic grasp of such people but are often directly within the realm of their understanding. Thus it is these societies that should logically, as well as morally, benefit first from this knowledge.

Manuscript received September 27, 2013; revised December 23, 2013.

The authors are with the Department of Construction Civil Engineering and Architecture, Faculty of Engineering, Polytechnic University of Marche, via Brecce Bianche1, 60131Ancona, Italy (e-mail: aymnajaj85@yahoo.com, f.pugnaloni@univpm.it).

\section{COMPACT URBAN FORM}

The severe prevailing climate, in most regions in the Arab world, necessitates planning fabric and house forms well adapted to the ambient environment. City planning was the first step for thinking. Minimal sun-exposure in summer and therefore compactness and shade are the main principals for building in hot-arid zones. Hence, compact planning for groups of buildings is required in order to give shade to each other (Fig. 1).

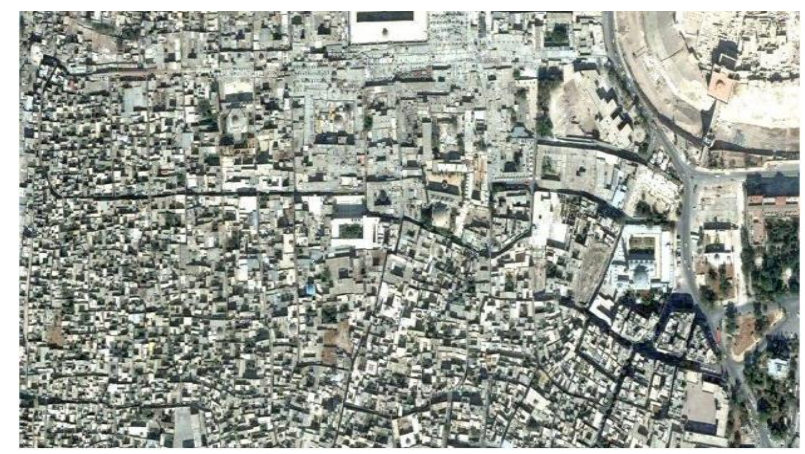

Fig. 1. Traditional urban fabric Aleppo, Syria

And to provide a shaded network of narrow streets (Fig.2a) and small spaces in between as patio-like areas. Arcades, colonnades, cantilevered buildings or building components, membranes and small enclosed courtyards are traditional responses to the climate; even larger public open spaces should be enclosed, inward looking and shaded for most of the day [2].

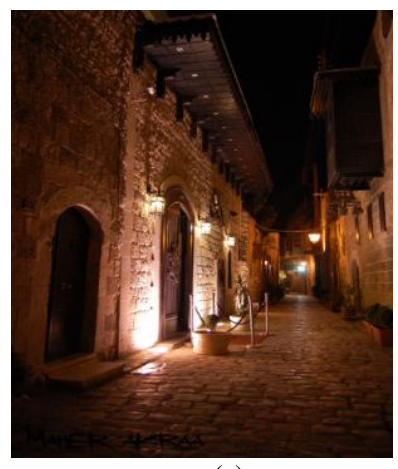

(a)

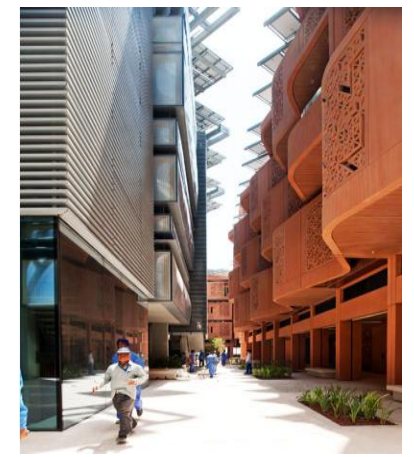

(b)
Fig. 2. (a) Narrow streets in old city of Aleppo.

(b) Contemporary reinterpretation of Narrow streets.

Urban fabric of the traditional Arab city is compact (Fig. 2) and the buildings are integrated into one complex structure in which it is hard to distinguish the individual houses, in order to avoid the sharp sunlight during summer and protection against extreme temperatures and sand storms, to minimize 
the thermal load on the buildings envelopes, especially houses .

Urban fabric in traditional cities was organic; thus most of the plots were irregular. To obtain the internal courtyard that was the central design for traditional houses, the regular geometric courtyard was the first to be planned. Then passageways and rooms were to be arranged around the courtyard. The irregular parts and undesirable angles were modified by changing the walls depth that may be used as shafts, service areas, niches, cabinets, or fixed furniture .

\section{ORIENTATION}

In selecting a suitable building orientation for a hot climate, where most of the Arab countries exist, the objective aim is to minimize the internal daytime temperature and to produce shaded exterior living space. Building and their continuous outdoor living spaces are oriented in a defensive posture against the wind-borne dust. To plan any site, the position of the sun must be determined for all hours of the day at all seasons as well as the direction of the prevailing winds, especially during the hot season.

For the direct rays of the sun, it is sufficient to know the angles of declination and altitude for the summer and winter solstices and the autumnal and vernal equinoxes. In addition, there will be reflection from adjacent buildings and wind shadowing by clusters of buildings, which contribute to specific microclimate for each building location.

Exposures $25^{\circ} \mathrm{E}$ of $\mathrm{S}$ secure balanced orientation, but all exposures are good from $\mathrm{S}$ to $35^{\circ} \mathrm{E}$. For bilateral buildings with cross ventilation, $12^{\circ} \mathrm{S}$ of $\mathrm{W}$ axis is preferred [1]

\section{DESIGN PHILOSOPHY}

Traditional house design philosophy is based on attaining two strategies: privacy and protection. These two strategies influenced the house layout, spatial relations, and architectural details. A central interior courtyard onto which all the rooms opened was restricted to family use. Courtyard provided an adequate climatic and social solution; it provided shading and privacy in an open space. Most of daily facilities were located at the courtyard.

Environmentally, courtyard was a thermal regulator, thus exposure to the sun is to be avoided and courtyards are to be kept small and overshadowed by high walls, wide eaves and foliage. In hot areas, where most of the Arab countries locate, courtyard functions in three phases. During the first phase, the cool night air descends into the courtyard and fills the surrounding rooms. Building structure even furniture are cooled at night and remain so until late afternoon. In addition, the courtyard loses heat rapidly by radiation to the clear night sky.

During the second phase, at midday, sun strikes the courtyard floor directly. Some of the cool air begins to rise and leaks out of the surrounding rooms. This induces convection currents that may afford further comfort. The courtyard now begins to act as chimney during this time when the outside temperatures are highest. During the third phase, the courtyard floor and the inside of the house get warmer and further convection currents are set up by late afternoon. Most of the cool air trapped within the rooms spills out by sunset. During the late afternoon the street, courtyard, and building are further protected by shadows of adjacent structures. As the sun sets in the hot arid zones, the air temperature falls rapidly as the courtyard begins to radiate rapidly to the clear night sky. Cool air begins to descend into the courtyard, completing the cycle.

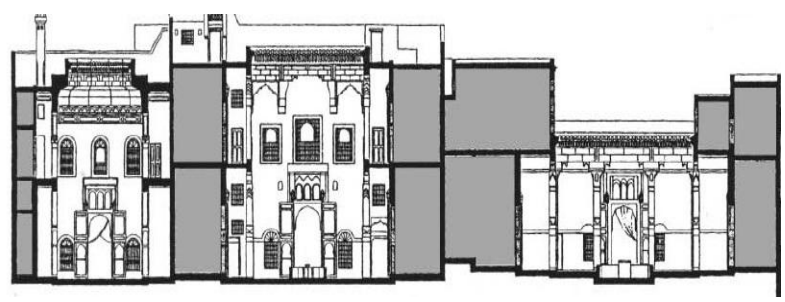

Fig. 3. Wall-to-wall built courtyard.

\section{BUILDING ENVELOPE AND MATERIALS}

The building envelope of a traditional house forms an effective barrier against the worst extremes of the external climate. It provides a filtering which modifies the climate sufficiently for the internal conditions to be more acceptable.

The main function of the house envelope is to resist the transference of heat, reflecting sun rays as much as possible, minimize the heat and solar gain to create cool conditions inside and counteract excessive solar gain .

Building envelope in traditional architecture was constructed of indigenous building materials that were appropriate of to ambient environment whether in physical properties to climatic conditions or the construction techniques employed by the society that produced this architecture.

Traditional building materials, such as brick, stone, palm trunks, and wood are usually natural, so they are generally low in embodied energy and toxicity. Often, traditional building materials are local and better suited to climatic conditions; thus, they create comfortable internal environment passively and naturally. They are low embodied energy, recyclable, reusable, energy efficient and environmentally sustainable. Undoubtedly, this is, in a way, in compliance with the Islamic principles of encouraging the use of indigenous materials .

Moreover, they were good thermal insulators when used as thick walls with minimum external openings. The almost solid elevations provided privacy for family especially for ground floor spaces. External treatments were simple reflecting humility and social equity.

\section{BUILDING COMPONENTS}

To control of heat transfer through thermal storage and time lag by proper construction.

\section{A. Openings}

Openings and windows are necessary for natural lighting and ventilation, but heat gain in summer should be minimal. During the daytime, the absence of openings would be desirable, especially on the west side; or the openings should be as small as possible and be shielded from direct radiation 
and located high on the walls to protect from ground radiation .

\section{B. Walls}

During the hot season, walls of daytime living areas should be made of heat-storing materials; walls of rooms for nighttime use should have a light heat capacity. East and west walls should preferably be shaded. High reflective qualities are desirable for both thermal and solar radiation.

\section{Roofs}

Different forms of roofs are possible or can be traditionally applied, the latter mainly determined by local materials and technical means. In hot-arid regions the vault, the dome and the flat roof are the traditional roof shapes.

\section{NATURAL VENTILATION}

Ventilation is essential and must be regulated to achieve the highest efficiency in keeping hot (and dusty) air out during the daytime, and cooling the thermal mass at night by air movement ;if possible together with outside vegetation [2], [3].

Natural ventilation was one of the passive cooling strategies that traditional architecture employed to create comfortable indoor climate through evaporative cooling. Traditional houses are oriented with respect to prevailing wind.

Blank facades are oriented to shield the outdoor living spaces from the hot winds while allowing adequate winter sunlight to penetrate the living zones. Wind movement and humidity also are important and should be considered simultaneously with the direct and indirect effects of the sun. Wind towers, Malqafs, Barjeels, or badgers (Fig. 4a) are the main natural ventilation features, along with courtyard and air pullers, formulate a complementary natural ventilation system for the house.

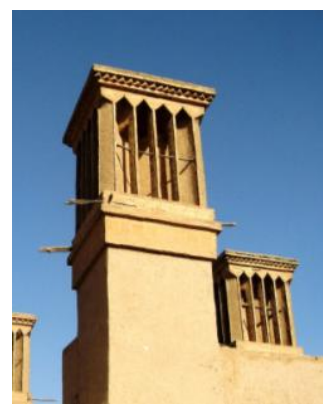

(a)

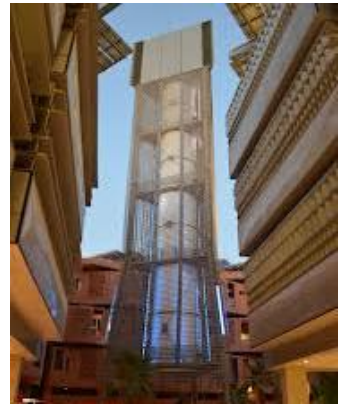

(b)
Fig. 4. (a) Traditional Malqaf.

(b) Contemporary reinterpretation of Malqaf.

The Architects were inspired by the design of wind towers that encourage airflow in pedestrian walkways. The wind towers used are the solar wind tower, also known as the solar chimneys (Fig. 4b).

\section{SHADING}

A major part of the heat a building gains is through solar radiation. This radiation is experienced in the form of increased air temperature, radiant heat and glare. Adequate shading reduces these effects drastically.

The further north or south from the equator, the bigger the difference of sun angles between winter and summer solstice. Together with shorter and longer days this yearly insulation cycle is responsible for the seasons. Luckily, winter sun penetrates more deeply south-oriented rooms at a time when warmth is needed. From April till October however, shading against direct sun is desired in most parts of the Arab Region [4].

Most important among these are the use of protrusions and cornices whether on outer facades or on the inner courtyard. Traditional house employ the roof garden as a way of reducing direct exposure to the sun, and use of the cloister (covered walkway) which protects the outer walls from direct sunlight.

The size and shape of the building determine the amount of shade. The area of shade increases with the degree of complexity of the building. Traditional houses have large areas of shade especially if there are parts of the building that rise more than one story. When the roof is not of one level the amount of shade will be greater than if it is of one level. The most remarkable shading devices is The Mashrabiya (Fig. 5a), which has five functions. Different patterns have been developed to satisfy a variety of conditions that require emphasis on one or more these functions.

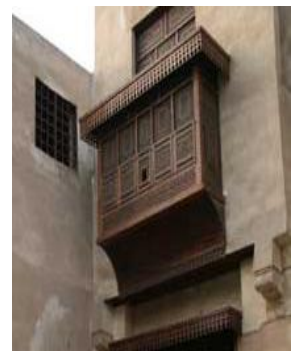

(a)

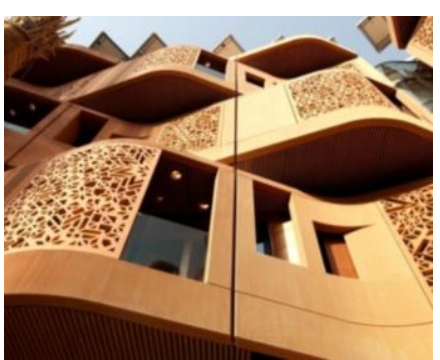

(b)
Fig. 5. (a) Traditional Mashrabiya

(b) Contemporary reinterpretation of Mashrabiya .

These functions involve: controlling the passage of light, controlling the air flow, reducing the temperature of the air current, increasing the humidity of the air current, and ensuring privacy. Each Mashrabiya design is selected to fulfill several or all of these functions. In the design, it is the sizes of the interstices (spaces between adjacent balusters) and the diameter of the balusters that are adjusted [5].

The Mashrabiya also inspired the design of the modern building's shading devices. Like the Mashrabiya, the design of the shades was both to filter the sun as well as create beautiful light and shade patterns (Fig. 5b) .

\section{PAssive CoOling}

In the Arab house, the fountain plays a role equivalent to the fireplace in the temperate zones, although one is used for cooling and the other for heating. Thus, the fountain is an architectural feature occupying a privileged place in the house plan.

\section{A. The Fountain}

Originally in the Arab house the fountain was placed in the 
middle of the courtyard with the Iwan or living spaces opened onto it. It always had a symbolic form, square in shape, with the inner basin in the form of an octagon or a hexadecagon . Thus the real sky is brought down into intimate contact with the Iwan by the reflection in the symbolic sky of the water basin.

After further development of the Arab house, the concept of the courtyard with several Iwan was transformed into the qã'a concept, composed of a Dur-qã'a, which is a covered courtyard, with the Iwan leading from it. In this arrangement, the fountain occupies a place in the center, displaying its water and mixing it with air to increase humidity [3] .

\section{B. The Salsabil}

In places where there was not enough pressure to permit the water to spout out of the fountainhead, architects frequently replaced the fountain with the Salsabil. The Salsabil is a marble plate, decorated with wavy patterns suggestive of water and wind, which is placed against the wall inside a niche on the opposite side of the Iwãn or sitting space. It is placed at an angle, to permit the water to trickle over the surface, thus facilitating evaporation and increasing the humidity of the surrounding air. The water then flows into a marble channel until it reaches the fountain in the middle of the Dur-qã'a.

The Salsabil can be interpreted as a transposition of the fountainhead placed outside the fountain, which shows mental flexibility and freedom of inventiveness in design. It allows the architect to use his creativity and sensitivity in expressing his feelings through architecture [3].

\section{CONCLUSION}

If architecture is considered as a part of nature, then the building must achieve the harmony with the ecological environment. As a result, this research provides a data for traditional architecture application for contemporary house.

The following strategies should be considered :

1) Provide maximum shading of direct and reflected sun radiation in the hot season.

2) Balance the extremes of summer and winter by movable parts.

3) Provide ventilation by regulated air movement and small openings.

4) Avoid large exposed exterior surfaces.

5) Use reflective outer surfaces.

6) Balance the extremes of day and night temperatures by adequate thermal storage mass.

7) Reduce internal heat production and conduction gain in hot seasons.

8) Promote evaporation and heat loss by radiation.

9) Increase air circulation in humid maritime regions.

And the environmental lessons to be learned from traditional architecture can be of significant value and relevance. Devices such as wind towers, the use of courtyards, The Mashrabiya, narrow streets and the various means of dealing with passive energy in traditional architecture, are appropriate and typical examples of green design.

The rich architectural heritage of the region should be carefully analyzed and understood in its own historic and physical context. Its human, cultural, and environmental values should be considered, adapted, and applied where relevant and appropriate in the context of contemporary conditions and technologies. It must be understood, however, that this is not a call for the adoption of traditional solutions to solve more complex and contemporary problems of different nature. Rather it is about the use of such concepts and devices in similar situations where the reintroduction and reinforcement of traditional values can contribute to the general environmental and cultural sustainability in a particular locality. It is also about the critical questioning of the appropriateness of those current modern practices in planning, urbanism, and architecture that have contributed to the deterioration of the quality of living environment in the Arab region and its general alienation ...

\section{REFERENCES}

[1] V. Olgyay, Design with Climate, Bioclimatic Approach to Architecture Regionalism, Princeton, New Jersey, 1962, pp.167.

[2] J. James, "Climate responsive building," Design for Hot Arid Zones, SKAT, pp. 159, 1993.

[3] H. Fathy, Natural Energy and Vernacular Architecture, The University of Chicago Press Chicago and London, pp.121-122, 1968.

[4] F. Ragette, Traditional Domestic Architecture of the Arab Region, Edition Axel Menges, pp. 86, 2003.

[5] H. Fathy, Natural Energy and Vernacular Architecture, The United Nations University by the University of Chicago Press, pp. 94, 1986.

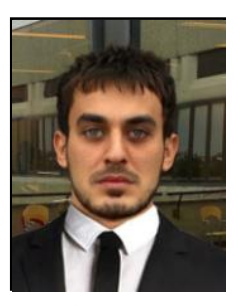

Marche.
Aiman Ajaj was born in Aleppo, Syria. He Graduated in Architecture Department, Private University of Science and Art, Aleppo (2009). He is a PhD student at Department of Construction Civil Engineering and Architecture, Polytechnic University of Marche in Ancona, Italy. His research work focus on architecture strategies in hot climate. He also collaborates to the teaching activity of "Architecture composition III" at Faculty of Engineering at Polytechnic University of

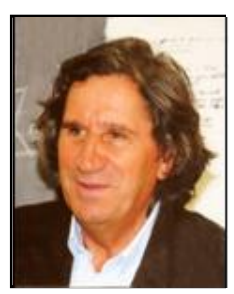

Fausto Pugnaloni was born in Italy. He is an architect, full professor of architectural design since 1994 at the Polytechnic University of Marche. He was Ex-Dean of the Department of Architecture Survey, Drawing, Urban Planning and History at the Faculty of Engineering, Ex-Dean of School of architecture and building engineering at the Faculty of Engineering at the Polytechnic University of Marche and deputy rector for International Relations of Polytechnic University of Marche in Ancona, Italy. He is full professor at the Beijing University of Civil Engineering and Architecture. He organized two workshops E-arcom, Technologies to communicate architecture. He organized conventions about conservation and exploitation of historical cities and sustainable urban planning. With UNIADRION (Telematic University of the Adriatic Ionian Basin) he works and studies about architecture and economy of the Adriatic coast. 